\title{
Benefits of total hip replacement to older patients and the community
}

\author{
G K WILCOCK
}

British Medical fournal, 1978, 2, 37-39

\section{Summary and conclusions}

The benefits of total hip replacement in 49 people aged 55-84 with osteoarthrosis of the hip were evaluated. The main benefit was relief of symptoms, 40 patients being pain free after operation. Range of hip movement and mobility improved moderately in most patients. After operation most patients were better able to perform certain activities of daily life, though only six were completely indc pendent, the rest requiring aids or help from others. Nevertheless, 18 of the patients' main helpers estimated that they had more time free of tasks previously performed for the patient. There was a small reduction in the need for community medical resources such as home visits from general practitioners or district nurses. Thirteen patients were still taking antiarthritic drugs. Older patients needed to spend longer in hospital after operation because of complications.

It was concluded that total hip replacement contributed to improving the quality of life of patients and their helpers, while also helping to reduce the demand for community health and welfare services.

\section{Introduction}

Attempts were made in the last century to perform operations on the hip joint. ${ }^{1}$ According to Scales these included an early attempt to use a hip prosthesis. ${ }^{2}{ }^{3}$ Most of the development of the modern hip prosthesis has, however, occurred during the past 25-30 years. Although originally reserved for older people with osteoarthrosis, total hip replacement is now often performed on younger patients and for different pathological conditions. Of the many studies evaluating the benefit of total hip replacement, some compare and contrast different hip prostheses-for example, Bentley and Duthie ${ }^{4}$ - and others evaluate one particular prosthesis. ${ }^{5-8}$ From these studies the outcome in more elderly patients with severe osteoarthrosis, who undergo most of the operations, cannot be ascertained, since people of widely differing ages and with different underlying diseases are usually assessed together as a single group.

I therefore designed a study to assess the outcome of total hip replacement with one of the more modern prostheses in patients

Department of the Regius Professor of Medicine, Radcliffe Infirmary, Oxford OX2 6HE

G K WILCOCK, DM, MRCP, clinical research fellow (now consultant physician in geriatric and general medicine, Cowley Road Hospital, Oxford OX4 1XB)

in the geriatric and pre-geriatric age range with osteoarthrosis of the hip. I aimed at evaluating the relief of symptoms and the effect of the operation on some of the activities of daily life, as well as investigating postoperative changes in the use of health and welfare services and the benefit to a patient's spouse or main helper.

\section{Patients and methods}

Men and women aged over 55 who were awaiting total hip replacement with Charnley's prosthesis for osteoarthrosis of the hip were included in the study. People who had previously undergone operation were included only if the first operation had been an osteotomy performed at least five years earlier, or a total hip replacement on the other hip at least nine months before. Thirteen men and 36 women aged between 55 and 84 (mean age 68) were studied. Each patient was studied during six months between April 1974 and December 1975. Assessments took place in the patient's home, the first during the week before operation, and the second six months later.

The assessment schedule was based on that developed by Garrad and Bennett, ${ }^{9}$ modified after consulting orthopaedic surgeons, rheumatology and rehabilitation specialists, occupational therapists and physiotherapists, and a medical social worker, all of whom had considerable experience in managing patients who had undergone hip replacement. A psychologist was also consulted. A pilot schedule was first tested on 10 people who had recently undergone hip replacement, and was subsequently modified to produce the schedule used in the main part of the study. Among the most important characteristics before and after operation were hip function and activities of daily living. The first of these was assessed according to the hip function index of D'Aubigne, as modified by Charnley ${ }^{11}$ (table I). In this the score for each of the three components is stated separately. A modified index of activities of daily living ${ }^{12}$ was used to score the following six activities: going outdoors; walking up and down stairs; getting about the house; washing and bathing; dressing and putting on shoes; cutting toenails. Each item was scored. separately on the following scale: $0-$ help required; 1 -no help required, but difficult; $2-$ no

TABLE I-Index used to assess hip function in patients before and after total hip replacement

\begin{tabular}{|c|c|c|c|}
\hline Score & $\begin{array}{l}\text { Range } \\
\text { of hip } \\
\text { movement }\end{array}$ & Pain & Mobility \\
\hline 1 & $0-30^{\circ}$ & Severe spontaneous pain & $\begin{array}{l}\text { Bedridden, or walks few } \\
\text { yards with two sticks or } \\
\text { crutches }\end{array}$ \\
\hline 2 & $31-60^{\circ}$ & $\begin{array}{l}\text { Prevents walking or severe } \\
\text { on walking }\end{array}$ & $\begin{array}{l}\text { Duration and distance very } \\
\text { limited with or without } \\
\text { sticks }\end{array}$ \\
\hline 3 & $61-100^{\circ}$ & $\begin{array}{l}\text { Tolerable with limited } \\
\text { activity }\end{array}$ & $\begin{array}{l}\text { Limited with one stick, } \\
\text { difficult without sticks. } \\
\text { Can stand for long } \\
\text { periods }\end{array}$ \\
\hline 4 & $101-160^{\circ}$ & $\begin{array}{l}\text { Present only after activity; } \\
\text { disappears quickly with } \\
\text { rest }\end{array}$ & $\begin{array}{l}\text { Long distance possible, but } \\
\text { limited without aids }\end{array}$ \\
\hline 5 & $161-210^{\circ}$ & Slight or intermittent, & No aids required, but has \\
\hline 6 & $210-260^{\circ}$ & None & Normal \\
\hline
\end{tabular}


difficulty and no help required. Individual scores were then added together to give a total score. These methods are discussed in more detail elsewhere. ${ }^{13}$

\section{Results}

CHANGE IN HIP FUNCTION SCORES

Range of movement-After operation 25 people had a range of hip movement (calculated by summating the range of passive hip movements) of more than 160 (grades 5 and 6) compared with none preoperatively (table II). Most people had an increased range of movement in their hip joint after surgery, but nine were the same as before operation. No person had less movement after surgery, most (35 patients) improving by one or two points on the scale (see figure).

Pain-Forty patients were pain free after operation (table III). Nevertheless, in one woman the grade was reduced from 3 to 2 . This patient had repeated postoperative dislocations, eventually requiring removal of the prosthesis. One other person did not improve, pain being scored grade 3 both before and after operation. Nineteen patients improved by three points, and 16 by four or five, indicating considerable pain relief (figure).

Mobility-Forty-five patients could walk long distances (grade 4 or greater) postoperatively, compared with only 10 before hip replacement (table IV). This included five people who could walk over a mile before hip replacement. Twenty-six of those who could walk long

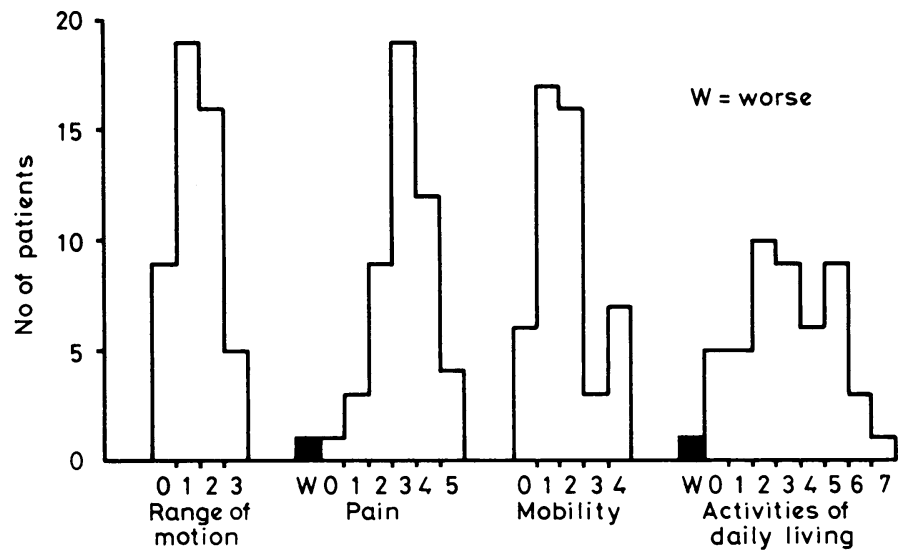

Changes in scores for hip function and activities of daily living in 49 patients after undergoing total hip replacement.

TABLE II-Scores for range of hip movement before and after total hip replacement. Figures are numbers of patients

\begin{tabular}{|c|c|c|c|c|c|c|c|}
\hline \multirow{2}{*}{$\begin{array}{l}\text { Preoperative } \\
\text { score }\end{array}$} & \multicolumn{6}{|c|}{ Postoperative score } & \multirow{2}{*}{ Total } \\
\hline & 1 & 2 & 3 & 4 & 5 & 6 & \\
\hline $\begin{array}{l}1 \\
2 \\
3 \\
4 \\
5 \\
6\end{array}$ & & & $\begin{array}{l}1 \\
1 \\
1\end{array}$ & $\begin{array}{l}1 \\
4 \\
8 \\
8\end{array}$ & $\begin{array}{r}3 \\
10 \\
9\end{array}$ & $\frac{1}{2}$ & $\begin{array}{r}2 \\
8 \\
20 \\
19 \\
0 \\
0\end{array}$ \\
\hline Total & 0 & 0 & 3 & 21 & 22 & 3 & 49 \\
\hline
\end{tabular}

TABLE III-Scores for pain before and after total hip replacement. Figures are numbers of patients

\begin{tabular}{|c|c|c|c|c|c|c|c|}
\hline \multirow{2}{*}{$\begin{array}{l}\text { Preoperative } \\
\text { score }\end{array}$} & \multicolumn{6}{|c|}{ Postoperative score } & \multirow{2}{*}{ Total } \\
\hline & 1 & 2 & 3 & 4 & 5 & 6 & \\
\hline $\begin{array}{l}1 \\
2 \\
3 \\
4 \\
5 \\
6\end{array}$ & & 1 & $\begin{array}{l}2 \\
1\end{array}$ & $\begin{array}{l}2 \\
1\end{array}$ & $\begin{array}{l}1 \\
1\end{array}$ & $\begin{array}{r}4 \\
12 \\
18 \\
6\end{array}$ & $\begin{array}{r}4 \\
17 \\
22 \\
6 \\
0 \\
0\end{array}$ \\
\hline Total & 0 & 1 & 3 & 3 & 2 & 40 & 49 \\
\hline
\end{tabular}

TABLE IV-Scores for mobility before and after total hip replacement. Figures are numbers of patients

\begin{tabular}{|c|c|c|c|c|c|c|c|}
\hline \multirow{2}{*}{$\begin{array}{l}\text { Preoperative } \\
\text { score }\end{array}$} & \multicolumn{6}{|c|}{ Postoperative score } & \multirow{2}{*}{ Total } \\
\hline & 1 & 2 & 3 & 4 & 5 & 6 & \\
\hline $\begin{array}{l}1 \\
2 \\
3 \\
4 \\
5 \\
6\end{array}$ & & $\begin{array}{l}1 \\
2\end{array}$ & 1 & $\begin{array}{r}10 \\
13 \\
3\end{array}$ & $\begin{array}{l}2 \\
2 \\
2 \\
1\end{array}$ & $\begin{array}{l}7 \\
1 \\
3 \\
1\end{array}$ & $\begin{array}{r}2 \\
21 \\
16 \\
8 \\
2 \\
0\end{array}$ \\
\hline Total & 0 & 3 & 1 & 26 & 7 & 12 & 49 \\
\hline
\end{tabular}

TABLE V-Scores on activities of daily living index before and after total hip replacement. Figures are numbers of patients

\begin{tabular}{|c|c|c|c|c|c|c|c|c|c|c|}
\hline \multirow{2}{*}{$\begin{array}{l}\text { Preoperative } \\
\text { score* }\end{array}$} & \multicolumn{9}{|c|}{ Postoperative score ${ }^{\dagger}$} & \multirow{2}{*}{ Total } \\
\hline & 4 & 5 & 6 & 7 & 8 & 9 & 10 & 11 & 12 & \\
\hline $\begin{array}{r}3 \\
4 \\
5 \\
6 \\
7 \\
8 \\
9 \\
10 \\
11 \\
12\end{array}$ & $\begin{array}{l}1 \\
1\end{array}$ & $\begin{array}{l}1 \\
3\end{array}$ & $\begin{array}{l}1 \\
1\end{array}$ & $\begin{array}{l}2 \\
3 \\
1 \\
1\end{array}$ & $\begin{array}{l}4 \\
1 \\
2 \\
1\end{array}$ & $\begin{array}{l}3 \\
4\end{array}$ & $\begin{array}{l}1 \\
3 \\
2 \\
2\end{array}$ & $\begin{array}{l}2 \\
1\end{array}$ & $\begin{array}{l}1 \\
2 \\
3\end{array}$ & $\begin{array}{r}1 \\
11 \\
12 \\
12 \\
13\end{array}$ \\
\hline Total & 3 & 4 & 2 & 7 & 8 & 8 & 8 & 3 & 6 & 49 \\
\hline
\end{tabular}

*No patient scored less than 3 preoperatively.

$\uparrow$ No patient scored less than 4 postoperatively.

distances still needed aids, as did the four patients who scored less than grade 4 . Only 12 people could walk without aids and without a limp. Of the people who scored grade 2 after surgery, one had intermittent claudication that had been masked preoperatively by hip disease, and another was the woman in whom the prosthesis had to be removed. There were no patients in whom mobility had deteriorated, although three people scored 4 both before and after operation, and one scored 5. Six remained in the same category. Most improved by one or two points, and 10 patients improved by three or four (figure).

\section{ACTIVITIES OF DAILY LIVING}

Thirty-three patients were graded 8 or more postoperatively on the activities of daily living score (table V), of whom only six were completely independent (grade 12), the others needing aids or help to perform certain activities. After operation there were still seven patients with scores of 4 or 5 , which meant that they could not carry out at least one or two activities (in practice often three), especially cutting toenails, having a bath, and climbing stairs. Twenty-eight patients gained at least three points on this scale, one of whom improved by seven points, and three by as many as six (figure). Only one person had a worse score after operation.

Thirty people still required walking aids outdoors, compared with 40 before operation, of whom 18 were still using the same aids, and four needed more help. Thirty patients, however, could climb stairs without restriction compared with only four previously. After hip replacement the number of patients who could not perform one or more of the domestic duties that they would normally have expected to do was reduced from 35 to 21 . Two people who had not been working before operation had taken up part-time employment and a third was working full time. Another was registered with an agency in an attempt to find work.

\section{USE OF HEALTH AND WELFARE SERVICES}

Only four of the nine people who had needed a home help could manage without after operation, but the two who had been visited by the district nurse no longer needed this. Fewer people (four compared with 12) required home visits from their general practitioner, and only 11 compared with 35 attended the surgery regularly (at least once every two months). Of these, seven consulted solely for hip symptoms and four for other chronic illnesses. 
Thirteen patients were still taking drugs for hip arthritis six months after their operation. This represented just over a quarter of the group studied, and in each case it was verified that the drugs were actually being taken for symptoms from the hip that had been operated on. Four patients were taking specific antiarthritic drugs, two aspirin, and seven other analgesics.

\section{EFFECT OF OPERATION ON PATIENTS' RELATIVES OR MAIN HELPER}

Ten of the 49 patients did not have a main helper. Among the remaining 39 , one-third of the main helpers did not think that the patient's operation had made any difference to their own pattern of life. Eighteen, however, estimated that they had gained at least an hour a day free of tasks previously undertaken for the patient. Two main helpers had also returned to full-time employment.

\section{COMPLICATIONS AND DURATION OF STAY}

The shortest stay in hospital after operation was 13 days and the longest 104 days (median 20 days). The mean length of stay was 23 days; 18 for patients aged under 70 (25 patients) and 28 for those aged 70 or more ( 24 patients). Fifteen patients had complications, five of these patients having more than one complication. The patients who had complications stayed in hospital on average for 30 days compared with 20 days for those who had no complications after operation.

\section{Discussion}

People who had undergone hip surgery previously were excluded from the study if they had other hip disease or if the past operations might have affected the assessment in some way. People who had undergone an osteotomy or total hip replacement were accepted, however, if they fulfilled the criteria outlined earlier, since it was thought unlikely that either of these operations would affect the assessment after a stable state had been reached.

Postoperative assessments were carried out after six months because most of the benefit from total hip replacement occurs by this time or earlier in most patients. ${ }^{14-16}$ All the assessments took place in the patient's own home to reduce the interaction that occurs between a subject and his observer when a test is taking place and also because patients perform worse when confronted by an unfamiliar observer in a strange environment. ${ }^{17-20}$ In addition, the validity of extrapolating the results of a hospitalbased assessment to a patient's home environment has been questioned. ${ }^{21} 22$ There are many problems inherent in any study using a questionnaire-interview technique. Space precludes discussion of these, but they have been considered in detail elsewhere. ${ }^{13}$

The results show that in this study, as in others, the main symptomatic benefit to the patient is relief of pain. Just over $80 \%$ of the patients were pain free-that is, they were "normal" in this respect. Moderate improvement also occurred in the other components of the hip function index. Among the improvements in the activities of daily living, some are more important than others. Mobility was obviously particularly important to the 10 people who did not have a main helper, and those who gained more independence when taking a bath and climbing stairs also benefited greatly, since these are activities which rely heavily on help from others.

The continued use of antiarthritic drugs after surgery is particularly interesting. Many patients may not have needed these drugs, though their effect might have influenced the assessment of benefit from the operation. If this was also true in other studies the benefits attributed to total hip replacement may be a little overestimated. The relatively high morbidity associated with antiarthritic drugs and the cost of these to the National Health Service is also important. The pattern of drug usage merits further study.

Some people past retiring age sought employment after operation because of economic pressures or for their own interest. In two instances a patient's main helper also obtained full-time employment. This emphasises the importance of looking beyond the patient himself when considering the benefit of hip replacement. The time reclaimed for their own purposes by many of the main helpers was also relevant, though less so.

Not surprisingly the more elderly patients needed to stay longer in hospital, partly because they took longer to rehabilitate after operation and partly because they had more complications. This finding should not, however, debar older people from hip replacement because in most cases the risks were greatly outweighed by the considerable pain relief resulting from a successful operation. The other benefits of total hip replacement, though not so dramatic as pain relief, nevertheless contributed to improving the quality of life of the patient and those around him. In addition there was a tangible, though modest, reduction in the need for community medical resources.

I thank Professor Sir Richard Doll for his help and advice, and my other colleagues in his department for providing invaluable help; Professor R B Duthie for allowing me to use the facilities of the Nuffield Orthopaedic Centre in Oxford and to study patients under his care, and for guiding me with his professional expertise; the many others, especially in the Nuffield Orthopaedic Centre, who gave constant help and encouragement in this project; the general practitioners who referred the patients; and the patients themselves.

The Medical Research Council provided the financial support for the study.

\section{References}

${ }^{1}$ Newman, $\mathrm{P} \mathrm{H}$, in Total Hip Replacement, ed M Jayson. London, Sector Publishing, 1971

${ }^{2}$ Scales, J T, fournal of Bone and foint Surgery, 1968, 50B, 698.

${ }^{3}$ Glück, T, Archiv für klinische Chirurgie, 1891, 41, 187.

${ }^{4}$ Bentley, G, and Duthie, R B, Clinical Orthopaedics and Related Research, 1973, 95, 127.

${ }^{5}$ Ring, P A, fournal of Bone and foint Surgery, 1974, 56B, 44.

${ }^{6}$ Charnley, J, and Cupic, Z, Clinical Orthopaedics and Related Research, 1973, 95, 9.

7 Chapchal, G, and Müller, W, Clinical Orthopaedics and Related Research, $1970,72,115$.

${ }^{8}$ Smith, R D, Clinical Orthopaedics and Related Research, 1970, 72, 177.

$\checkmark$ Garrad, J, and Bennett, A E, British fournal of Preventive and Social Medicine, 1971, 25, 97.

${ }^{10}$ D'Aubigne, R M, in Proceedings of 4th Congress of Societe Internationale de Chirurgie Orthopédique et de Traumatologie, ed M J Delchef. Brussels, Lilien, 1950.

11 Eftekhar, N S, Clinical Orthopaedics and Related Research, 1971, 81, 93.

12 Shanas, E, et al, Old People in Three Industrial Cities. London, Routledge and Kegan Paul, 1968.

13 Wilcock, G K, DM Thesis. Oxford University, 1977.

${ }_{14}$ Murray, M P, et al, fournal of Bone and foint Surgery, 1971, 53A, 259.

15 Johnston, R C, Clinical Orthopaedics and Related Research, 1973, 95, 118.

16 Pugh, L G C E, fournal of Bone and Foint Surgery, 1973, 55B, 742.

17 Wolf, S, fournal of Clinical Investigation, 1950, 29, 100.

18 Osgood, C E, and Suci, G J, Psychological Bulletin, 1952, 49, 251.

19 Cole, S L, and Griffith, G C, fournal of the American Medical Association, $1958,168,275$.

${ }^{20}$ Kelman, H R, and Willner, A, Archives of Physical Medicine and Rehabilitation, 1962, 43, 172.

21 Townsend, P, The Last Refuge. London, Routledge and Kegan Paul, 1962.

22 Carroll, D G, in Motivation of the Physically Disabled, ed P J R Nicholls and W H Bradley. London, National Fund for Research into Crippling Diseases, 1968

(Accepted 20 April 1978)

What is the likelihood of inheriting myotonia atrophica?

Myotonic dystrophy behaves as a regular dominant condition; therefore the risk of a child of a patient with the disease inheriting the gene and later developing the disease is 1 in 2 . The severity of the disease is very variable even within the same family. ${ }^{1}$ The affected mutant gene is linked to that for secretor status. ${ }^{2}{ }^{3}$

Bunday, S, and Carter, C O, fournal of Medical Genetics, 1972, 9, 311.

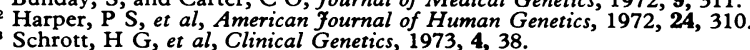

